Alfaro Suescun, E. (2020): “Iglesia, cementerio y aldea en Álava durante el siglo XII. ¿Evidencias materiales de la implantación parroquial?", Spal 29.1: 301-320. DOI: http://dx.doi.org/10.12795/spal.2020.i29.11

\title{
IGLESIA, CEMENTERIO Y ALDEA EN ÁLAVA DURANTE EL SIGLO XII ¿EVIDENCIAS MATERIALES DE LA IMPLANTACIÓN PARROQUIAL?
}

\section{CHURCH, CEMETERY AND VILLAGE IN 12TH CENTURY ÁLAVA (SPAIN). MATERIAL EVIDENCE OF THE ESTABLISHMENT OF THE CATHOLIC PARISH?}

\author{
EGOITZ ALFARO SUESCUN \\ Universidad del País Vasco / Euskal Herriko Unibertsitatea \\ Centro de Investigación Micaela Portilla. c/ Justo Vélez de Elorriaga, 1. 01006 Vitoria-Gasteiz (Álava) \\ Correo-e: egoitz.alfaro@gmail.com. (D) http://orcid.org/0000-0002-7617-0490 \\ Researcher ID: <https://publons.com/researcher/H-9320-2017>
}

\begin{abstract}
Resumen: En el presente artículo se analizan los registros arqueológicos plenomedievales (siglos XI-XIII) de seis aldeas de Álava (Armentia y los despoblados de Zornoztegi, Zaballa, Aistra, Torrentejo y Dulantzi), poniendo el acento en las iglesias, sus estructuras asociadas y su relación con las unidades domésticas del entorno. El objetivo es doble. Por un lado, determinar si se produjeron transformaciones generalizadas y coincidentes en el tiempo. Por otro, y en el caso de identificarlas, establecer si tuvieron relación con la implantación de la red parroquial, proceso casi exclusivamente estudiado desde las fuentes escritas. Se confirmarán ambas cuestiones, subrayando la heterogeneidad del proceso. Así, en la discusión se definirán los diversos escenarios sobre los que se estableció la parroquia y se evaluarán los variados marcadores materiales empleados para su reconocimiento.
\end{abstract}

Palabras clave: Plena Edad Media; marcadores materiales; rentas eclesiásticas; iglesias propias; poderes episcopales; comunidades aldeanas.
Summary: This paper analyses the archaeological record of six villages of Álava, north-central Iberia, in the High Middle Ages (11-13th centuries AD): Armentia and the deserted villages of Zornoztegi, Zaballa, Aistra, Torrentejo and Dulantzi. The approach focuses on their churches, their associated structures and the relationship with the surrounding domestic households, with a double aim. First, to establish if these elements were subject to widespread and synchronic transformations. Second, to assess whether these changes, if identified, had any connections with the implementation of the Catholic parish network, a process that so far has been almost exclusively studied after the written sources. The results come to confirm both issues, showing the notable heterogeneity of the process in the territory. The discussion serves here to define a set of diverse scenarios for the establishment of the parish and to evaluate the different material markers used for their identification.

Keywords: High Middle Ages; material markers; ecclesiastical rents; proprietary churches; episcopal powers; peasant communities. 


\section{INTRODUCCIÓN}

En el estudio de las iglesias, tanto desde una perspectiva monumental como del paisaje, la arqueología del centro-norte peninsular ha puesto el acento principalmente en las cronologías altomedievales (p. ej. Caballero 2001, Caballero y Utrero 2005, Utrero 2006, Sánchez Zufiaurre 2007, Quirós 2011). Los templos construidos o reformados a partir del siglo XI apenas han recibido la atención de los arqueólogos, proviniendo las principales aportaciones desde la historia del arte. Su coincidencia cronológica con el estilo románico ha generado una abundante bibliografía sobre estos edificios de culto desde hace tres décadas (p. ej. los diversos volúmenes de la Enciclopedia del Románico editados por la Fundación Santa María la Real).

Los escasos trabajos que desde la arqueología se han ocupado de estas cuestiones han hecho referencia a algunas de las transformaciones asociadas a estas iglesias, pero sin buscar una comprensión integral. En una reciente publicación señalábamos los cambios que se produjeron en las funciones, significados, promotores y actores de las iglesias de Álava y Treviño durante y a partir del siglo XII. Tanto la oferta como la demanda se modificaron de manera profunda, mostrándonos un escenario en el siglo XIII radicalmente diferente al que había existido hasta el siglo XI (Alfaro 2017). No obstante, dicho estudio, que se desarrolló en el ámbito de la arqueología de la arquitectura, se limitaba a los caracteres constructivos de los templos, sin tener en cuenta otras transformaciones que ocurrieron en sus estructuras asociadas, así como en el propio caserío circundante.

Del mismo modo, hay otras publicaciones que se han centrado en cómo cambiaron las necrópolis durante estos siglos, documentando la transición de las «altomedievales» a las «parroquiales» (García Camino 2002, Gutiérrez Cuenca 2015). De nuevo, faltaría un enfoque holístico que integre y explique todas las transformaciones que se visibilizan durante estos siglos en el registro arqueológico.

Esta desatención ha provocado que la arqueología medieval del norte peninsular apenas haya hecho hincapié en la red parroquial como instrumento de análisis social, más allá de considerarlo un fenómeno tardío en el marco de la feudalización. Ello contrasta con la amplia producción científica desarrollada desde las fuentes escritas sobre la parroquia pleno y bajomedieval.

Aludimos a este tipo de parroquia porque este es un término polisémico que no hace referencia a una única realidad inmutable o intrínseca a la organización de la sociedad cristiana. Por ejemplo, y sin querer ser exhaustivos, G. Ripoll e I. Velázquez diferencian hasta tres acepciones de parrochia en las actas conciliares de los siglos VI y VII (Ripoll y Velázquez 1999: 113-121, 142-144, 156). Asimismo, y para la diferenciación de estas parroquias de los albores de la Edad Media con las que nos atañen, remitimos a los trabajos de F. López Alsina (antigua-clásica) y de J. Á. García de Cortázar (gentilicia-de aldea) (López Alsina 1999: 264-265, 277 , 284-285; García de Cortázar 1988: 90-92).

En relación con las parroquias pleno y bajomedievales, los historiadores coinciden en que durante este periodo se fijó en Europa occidental una red con diversos rasgos comunes: un templo, un territorio delimitado, una comunidad que paga rentas a cambio de enterrarse y recibir sus sacramentos, y un presbítero que se encarga de administrarlos. Estas características son casi unánimemente mencionadas por los autores que se han ocupado de la temática, aunque casi siempre destacando unas sobre otras (Le Bras 1975: 227, García de Cortázar 1988: 90, Etxezarraga 2011: 89, Curiel 2009: 35, López Alsina 1999: 264, Ruiz de la Peña 2008: 199). Enrique de Segusio, eclesiástico que vivió a mediados del siglo XIII, incluyó ya esta triple dimensión templo-territorio-comunidad de la parroquia en su obra Summa aurea (Lauwers 2005: 29).

En el proceso de implantación parroquial se asumen ritmos y procesos variados condicionados por los diferentes puntos de partida (López Alsina 2006: 421422 , 425). A modo de ejemplo para la península ibérica baste mencionar las tempranas cronologías que la historiografía baraja para la extensión de la red parroquial en Cataluña, siglo XI o anterior (Villaginés 1988, To Figueras 1991, Martí 2006), en comparación con la de otras regiones del centro-norte peninsular, como Vizcaya (García Camino 2002), Asturias (Ruiz de la Peña 1993: 108, Calleja 2000) o Soria (Asenjo 1999: 393-396), donde se proponen los siglos XII-XIII o, incluso, el siglo XIV para el caso de Guipúzcoa (Etxezarraga 2011).

Sin embargo, los aspectos definitorios de la institución comentados, especialmente la territorialidad y la administración de sacramentos, no son fácilmente aprehensibles desde el registro material, hasta el punto de que podríamos cuestionarnos si la praxis arqueológica es un método válido para reconocer un proceso como el de la formación parroquial, con grandes variaciones en sus rasgos y cronologías a diferentes escalas.

El objetivo del presente trabajo es, en este sentido, analizar las secuencias ocupacionales de diversos yacimientos del Territorio Histórico de Álava, 


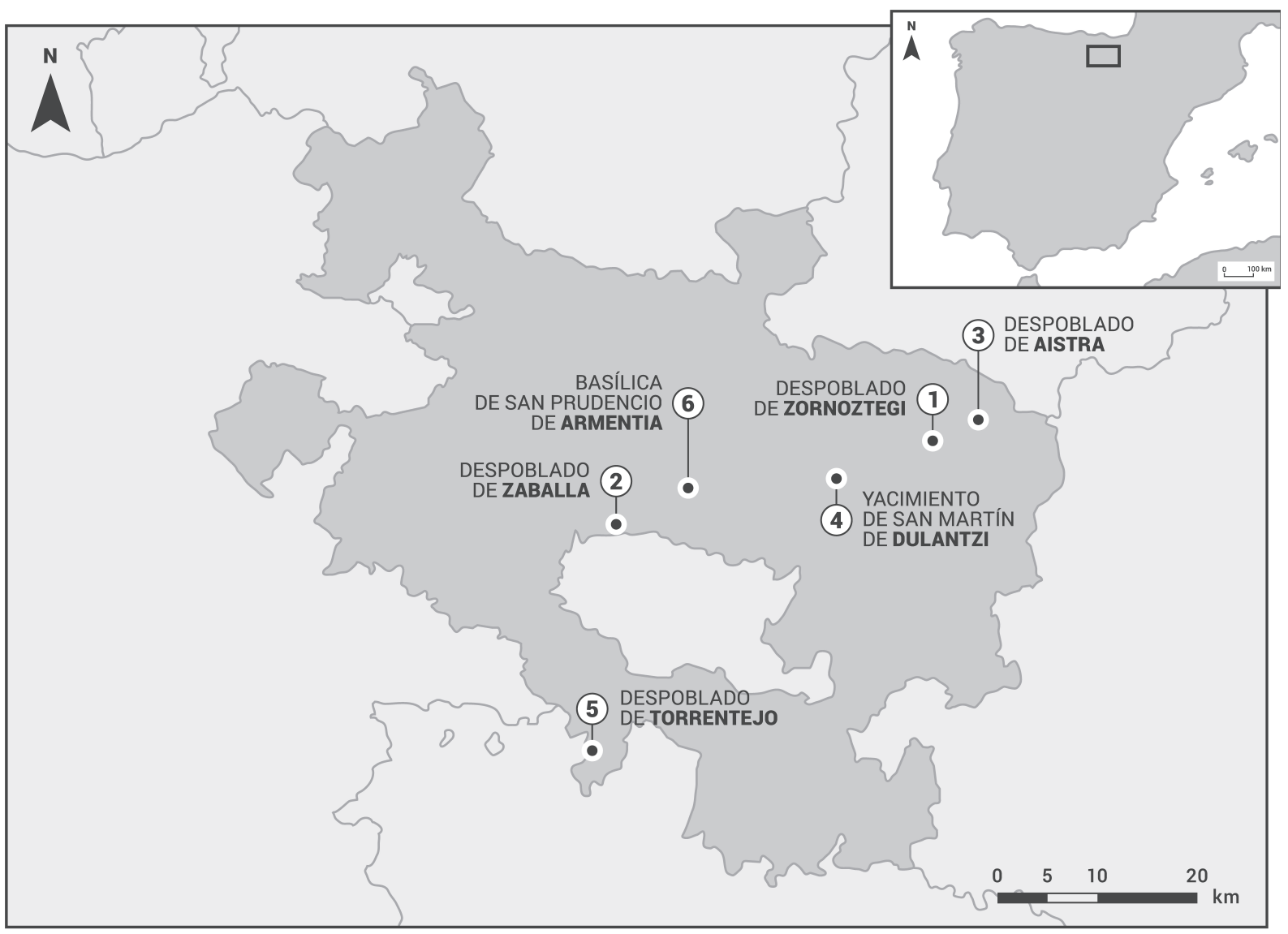

Figura 1. Mapa con el ámbito geográfico y los casos de estudio considerados en el artículo.

centrándonos en las fases plenomedievales de los edificios de culto, sus estructuras asociadas (cementerios, espacios de almacenaje o de habitación) y su relación con las unidades habitacionales y productivas del entorno. Pretendemos, así, responder a las siguientes preguntas: ¿es posible identificar de forma generalizada transformaciones de calado durante estos siglos? De ser así, ¿pueden ser asociadas a la parroquia?

Se trata, en definitiva, de valorar la potencialidad de la arqueología para analizar un fenómeno, el de la formación de la red parroquial, tradicionalmente estudiado desde la documentación escrita. Por ello, no se tendrán en cuenta aspectos del mismo que no puedan ser identificados materialmente.

\section{CASOS DE ESTUDIO}

En este apartado analizaremos seis yacimientos arqueológicos, describiendo sus secuencias de ocupación y poniendo el acento en la evolución constructiva de las iglesias. El objetivo es identificar los cambios que se produjeron durante los siglos XI-XIII tanto en la materialidad de los edificios de culto como en la relación de estos con el poblamiento circundante.

Hemos seleccionado estos casos de estudio por un doble motivo. Por un lado, se trata de yacimientos excavados en extensión y estudiados de forma transdisciplinar, aunque todavía alguno esté a la espera de ser publicado. Por otro, hacen referencia a contextos aldeanos y rurales de diversa naturaleza que remiten a puntos de partida y trayectoria diferentes, lo que enriquece el análisis comparativo. Hemos obviado deliberadamente los asentamientos de carácter urbano por considerar que la atracción que ejercieron hacia diferentes poderes complica la interpretación de los cambios acaecidos durante estos siglos. De hecho, en nuestra investigación arqueológica sobre la villa de Treviño (Burgos) concluíamos que su condición de centro organizador del territorio le otorgó un carácter multifocal que atrajo a 


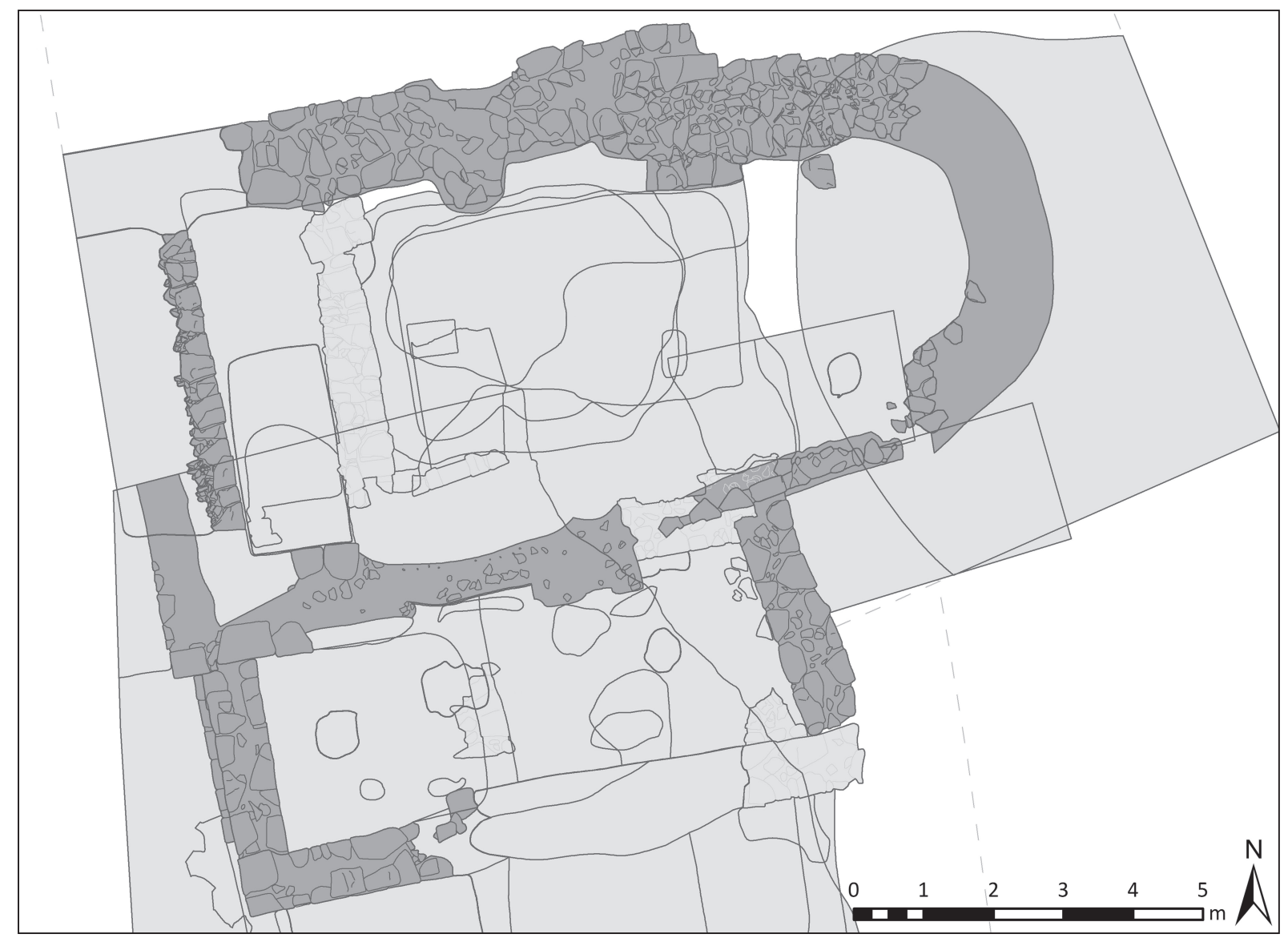

Figura 2. Zornoztegi. Planta de la iglesia y su pórtico meridional (fuente: Gipypac, UPV-EHU).

poderes de diversa naturaleza. Sugeríamos que la influencia de la parroquia, como instrumento de poder diocesano, había sido más limitada en esta villa que en el resto de aldeas estudiadas. La influencia de estos poderes debió de condicionar desde el principio el estatus de las iglesias de Treviño y su control efectivo por parte de la sede calagurritana, en especial mediante la figura del patronato (Alfaro 2016: 116-117).

\subsection{El despoblado de Zornoztegi (Salvatierra)}

El yacimiento de Zornoztegi se encuentra en el término municipal de Salvatierra, en la mitad oriental de la llanada alavesa. Ocupa casi 2 ha de extensión y está diferenciado en tres sectores: la cima del cerro ocupada por monte bajo, una plataforma elevada conocida con el nombre de Ubaide y la base de la colina formada por laderas poco pronunciadas. Fue excavado, afectando a $3.533 \mathrm{~m}^{2}$ de terreno, a lo largo de cinco campañas, entre 2005 y 2009, bajo la dirección de J. A. Quirós (Universidad del País Vasco UPV-EHU). Su secuencia ocupacional, exceptuando ciertos restos aislados de cronología calcolítica, se extiende entre el final de la Antigüedad (siglos IV-V) y el final de la Edad Media (siglo XIV-primer cuarto del XVI) (Quirós 2018).

Los periodos relevantes para nuestro estudio son el 4 y el 5. El periodo 4 (siglos VIII-XI) comprende la creación y desarrollo de la aldea de Zornoztegi. En este momento se identifican exclusivamente estructuras domésticas, de habitación y almacenaje, realizadas en materiales perecederos y localizadas en la plataforma Ubaide.

Durante el periodo 5 (siglos XII y XIII) se edifica una iglesia y su necrópolis asociada en la zona más elevada de Ubaide, así como algunas estructuras domésticas en la ladera norte de la colina. El templo dispuso de orientación canónica E-O, una sola nave, ábside semicircular, planta rectangular y pórtico al sur. Fue construido empleando mampuestos calizos de origen local 


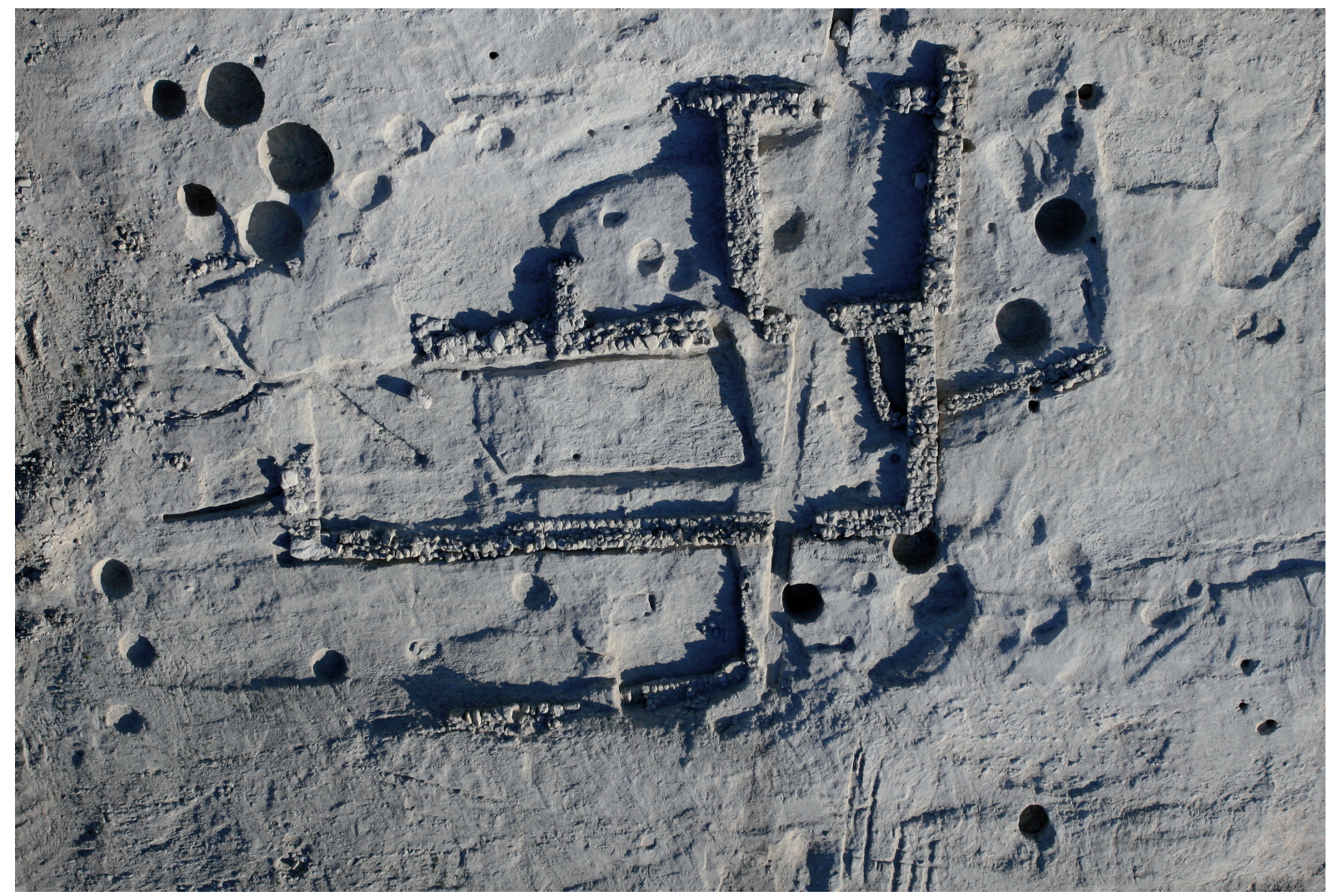

Figura 3. Zaballa. Fotografía aérea de la iglesia y su pórtico sur (en la mitad inferior) (fuente: Gipypac, UPV-EHU).

para los muros y caliza paleocena exógena para los esquinales y vanos. El carbono-14 y la morfología de la cabecera fechan su construcción en la primera mitad del siglo XII.

Al sur del pórtico se sitúa el área cementerial. En ella se identificaron seis inhumaciones, de las que se excavaron tres, y un osario. Los tres enterramientos eran de fosa simple y tenían abundantes evidencias de reutilización. Gracias a su secuencia vertical, y pese a su escaso número, es posible verificar la presencia de varias fases en la necrópolis, que debió extenderse hasta el abandono de la aldea en el siglo XIV (Mendizabal 2013).

La edificación del templo produjo una redefinición funcional del espacio en Ubaide, que adquirió una novedosa finalidad litúrgico-funeraria, amortizando la anterior de carácter doméstico y que llevaba en uso desde el siglo X. Coincidiendo con estos cambios, el extremo meridional de la aldea dejó de emplearse con fines domésticos y se transformó en un espacio de producción agrícola, mientras que el hábitat se dispuso alrededor del nuevo templo (Alfaro 2018).

\subsection{EI despoblado de Zaballa (Nanclares de la Oca)}

El término de Zaballa se sitúa en el extremo suroccidental de la llanada alavesa y en el ángulo sudeste del municipio de Iruña de Oca. El yacimiento se divide en dos sectores principales: una plataforma situada al nordeste (área 6000) y el valle adyacente (áreas 3000, 4000 y 5000).

Dirigida por J. A. Quirós, la intervención arqueológica se llevó a cabo debido a la intención de construir el Centro Penitenciario Norte I en este término. Se realizó una primera valoración arqueológica en julio de 2007 y pasó a excavarse en extensión a lo largo del siguiente año.

En una superficie intervenida de $46.055 \mathrm{~m}^{2}$ se identificó una secuencia ocupacional que comenzaba en el siglo VI y se extendía ininterrumpidamente hasta el siglo XVI, tras lo cual se produjeron ciertas ocupaciones de carácter marginal y, finalmente, la construcción de un polvorín militar en el siglo XX (Quirós 2012).

Nos referiremos a los periodos 2, 3 y 4, al ser los únicos relevantes para nuestro trabajo. Durante el periodo 2 (siglos VIII-X) se levantaron, en la plataforma y parte del 
valle (áreas 6000 y 3000), las estructuras domésticas que conformaban la aldea. El periodo se divide en dos fases, diferenciadas en función de los caracteres constructivos de las edificaciones: materiales perecederos en la primera (hasta el siglo X), arquitectura mixta en la segunda.

En un periodo indeterminado del siglo $\mathrm{X}$ se produjeron las transformaciones que definen el periodo 3 (hasta la primera mitad del siglo XIII): edificación de una iglesia en el área 6000 que amortizó el espacio doméstico precedente; densificación de la ocupación doméstica en el área 3000; construcción de las primeras terrazas de cultivo (áreas 4000 y 5000).

El edificio de culto contó con una orientación NE$\mathrm{SO}$, nave única, acceso al sur, ábside recto no diferenciado, una necrópolis y diversos silos de almacenaje asociados. Está realizado en mampostería, aunque empleando piezas talladas de mayor calidad para vanos y accesos, como sugieren los fragmentos hallados en depósitos secundarios más tardíos. Se fecha en el siglo X gracias a la datación radiocarbónica de un carbón recuperado de la zanja de cimentación de uno de sus muros.

En una fase posterior se dotó de un pórtico en su acceso sur. Esta acción constructiva está datada en el siglo XII a partir del carbono-14 de una semilla hallada en una de sus zanjas de fundación.

Cinco son los silos que pueden ser asociados al templo con total seguridad, todos ellos en el exterior. Los dos más antiguos, contemporáneos a la construcción de la iglesia, no están agrupados y destacan por su gran diámetro ( $>2{ }^{\prime} 5 \mathrm{~m}$ ), que sobrepasa ampliamente el de los silos de carácter doméstico del periodo anterior (promedio, en adelante $x^{\prime},=1,54 \mathrm{~m}$. Los tres silos restantes tienen un diámetro más reducido $\left(x^{\prime}=1,43 \mathrm{~m}\right)$ y son más tardíos (siglos XI-XIII).

Del cementerio de la iglesia de Zaballa se han podido recuperar 19 enterramientos, todos ellos en fosa simple excepto una tumba de lajas. Se emplazaba al norte, una ubicación poco común, y más si tenemos en cuenta que ni al este ni al sur se ha identificado ninguna inhumación a pesar de que eran espacios vacíos. Con todo, su relación con el templo está fuera de toda duda al mantener su misma orientación NE-SO y porque la única datación radiocarbónica realizada en una de las tumbas es coincidente con el periodo 3 .

Durante el periodo 4 (segunda mitad del siglo XIIImediados del XV) se produjo una reforma del complejo eclesial, la construcción de nuevos edificios adosados al norte y una proliferación de elementos de carácter habitacional en el área, que llevará, ya en la Edad Moderna (periodo 5) a su reutilización como estructura doméstica.

\subsection{El despoblado de Aistra (Zalduondo)}

El despoblado de Aistra se emplaza en el extremo nororiental de la llanada alavesa, al noroeste de la villa de Zalduondo y a los pies de los montes de Altzania. La intervención arqueológica de mayor calado corresponde al proyecto desarrollado entre 2006-2009 y dirigido por J. A. Quirós y A. Reynolds (University College London). En una extensión total de $2.744 \mathrm{~m}^{2}$ se definió una ocupación ininterrumpida desde el siglo VI hasta el siglo XIV (Reynolds y Quirós 2010), en la que destacaremos para nuestro trabajo los periodos 2, 3 y 4 .

En el periodo 2 (siglo VIII-primera mitad siglo X) comienza a emplearse un espacio próximo a la aldea, creada en el siglo VI, como espacio cementerial exento, no asociado a ningún edificio de culto. La campaña de 2009 sacó a la luz 54 sepulturas de esta necrópolis, organizadas en hiladas y alineadas E-O. Ninguna de ellas tenía ajuar y disponían de una tipología variada que incluía tumbas de fosa simple (40\%), de lajas (33\%) y de murete $(27 \%)$. Nunca se superponían, por lo que suponemos que se señalizaban de algún modo. Siete de estos enterramientos mostraban además evidencias de reutilización, aunque nunca con más de dos individuos (Mendizabal 2011: 413, 416-419).

El evento más destacable del periodo 3 (segunda mitad del siglo X-siglo XII) fue la construcción de una iglesia y de una nueva necrópolis a su alrededor durante la décima centuria. Se erigieron sobre un lugar aparentemente periférico de la aldea, vacío hasta ese momento. De forma paralela, se produjo el abandono de parte de las estructuras domésticas del periodo anterior.

Esta iglesia sobrevive hoy en día como ermita con la advocación de San Julián y Santa Basilisa. Tanto la tipología del ventanal monolítico orientado al este (García Camino 2002: 175-181), como la excavación de los cimientos del muro norte en 2006 (Reynolds y Quirós 2010: 38, 39) coinciden en que fue erigida a mediados del siglo $\mathrm{X}$.

Los restos conservados del siglo $\mathrm{X}$ aportan pocos datos sobre las características de la iglesia primitiva: cabecera recta y una única nave. Fue construida con bloques nuevos de cantera de arenisca albiense que se asemejan a sillares desde el exterior, pero que son en realidad lajas gruesas entre las que se dispuso un núcleo compuesto de mampuestos y argamasa. El empleo de esta litología alóctona de difícil talla y la presencia del vano monolítico reflejan la presencia exclusiva de canteros en la construcción del edificio.

La necrópolis que se establece en el periodo 3 alrededor de la iglesia ha sido atestiguada en diversas 


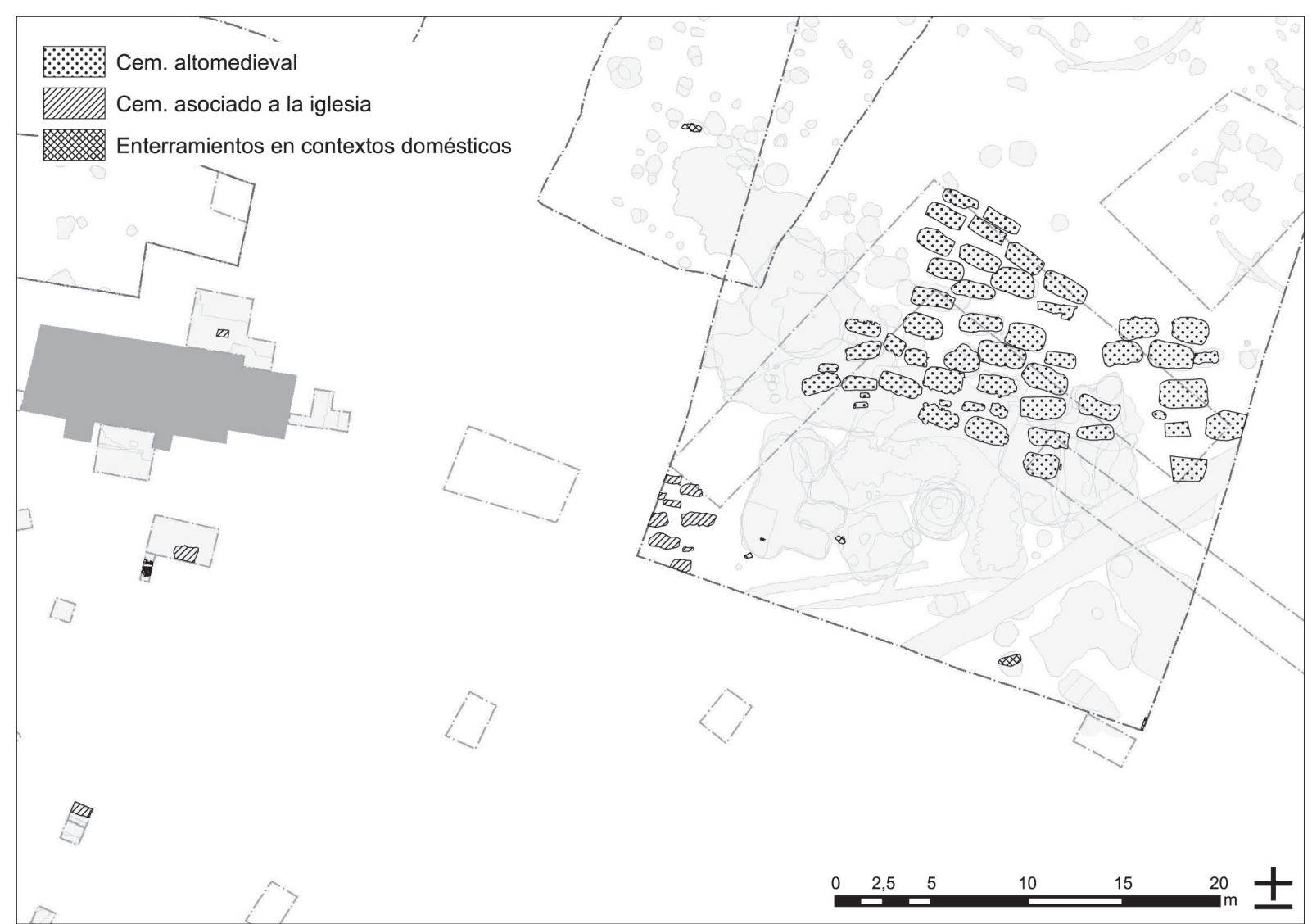

Figura 4. Aistra. Planta con todos los enterramientos identificados en las campañas 2006-2009 y la iglesia del siglo X (a la izquierda) (fuente: Gipypac, UPV-EHU).

campañas de excavación llevadas a cabo desde los 80 . Ya en 1982 se identificaron 27 tumbas con un claro predominio de las realizadas mediante lajas respecto a las de fosa simple (25-2) (García Retes 1987: 457-459). En campañas más recientes se excavaron seis individuos más dispuestos en una fosa de forma ordenada, aunque sin ningún elemento de separación entre ellos (GarcíaCollado 2011: 91-92).

Es importante precisar que la creación del cementerio asociado al templo no supuso el abandono de la necrópolis altomedieval de forma inmediata. Parece que ambos coexistieron a lo largo del siglo $\mathrm{X}$, quizá incluso más allá (García-Collado 2011: 67-69).

Más adelante, ya en el periodo 4 (siglos XI-XV), tuvo lugar una reforma de la iglesia, posiblemente en el siglo XII, aunque no hay ningún indicador cronológico que le asocie una cronología absoluta. Se presupone que fue realizada en esta centuria porque cuenta con elementos, como los canecillos, típicos del estilo románico.
La reforma, en cualquier caso, fue llevada a cabo cuando la iglesia primitiva se hallaba en buena medida arruinada, y supuso la reconstrucción de la cabecera y la ampliación de la nave en anchura. La obra fue dirigida por albañiles, como refleja el hecho de que se reutilizaran bloques de la fase anterior y se dispusieran con múltiples engatillados e irregularidades. No obstante, para algunos elementos puntuales como los canecillos, y quizá la cornisa, es evidente que se solicitó la colaboración de canteros.

\subsection{El yacimiento de San Martín de Dulantzi (Alegría-Dulantzi)}

Se localiza en la villa de Alegría-Dulantzi, en plena llanada alavesa y a medio camino entre Vitoria-Gasteiz y Salvatierra. En concreto, se ubica en el espacio que ocupaba la desaparecida aldea de Dulantzi, al norte del casco histórico de la villa y al otro lado del río Alegría. 
Los hallazgos relativos a la aldea de Dulantzi salieron a la luz en dos fases, la primera durante los años 2009-2010 y la segunda en 2014, ambas dirigidas por los arqueólogos M. Loza y J. Niso, de la empresa Iterbide SC.

La secuencia ocupacional del yacimiento se dividió en ocho fases que abarcan un amplio lapso entre el segundo milenio a.C. y el siglo XX (Loza y Niso 2016, Alfaro et al. 2017: 249-250). Las más significativas para nuestro trabajo son las cuatro fases medievales (4-7).

La fase 4 (segunda mitad del siglo VI-finales VII) se inicia con la construcción de una iglesia de grandes dimensiones y un cementerio asociado sobre el espacio doméstico, y quizá funerario, anterior. El templo tuvo una orientación canónica, ábside diferenciado, recto por el exterior y semicircular por el interior, y tres naves. Contaba, asimismo, con un baptisterio de planta rectangular imbricado al muro sur de la nave y una estancia parcialmente conservada al sur de la cabecera. Todos sus muros fueron elaborados con una misma técnica constructiva a base de lajas, mampuestos careados y elementos reaprovechados de época romana trabados con argamasa. Su fecha de construcción, años centrales del siglo VI, viene determinada a partir de las relaciones estratigráficas, el carbono-14 y los materiales cerámicos.

En esta fase el cementerio tiene un carácter exclusivo. Acogía en el interior de la iglesia solo a individuos destacados, como demuestran los análisis antropológicos, isotópicos y, en algunos casos, los materiales con los que fueron enterrados.

Durante la fase 5 (finales del siglo VII-siglo X) esta necrópolis dejó de ser un espacio funerario privilegiado y pasó a serlo de toda la comunidad aldeana, inhumándose en el exterior de la iglesia y con una gran variedad tipológica en las tumbas, que además ya no tienen ajuares.

La fase 6 (segunda mitad del siglo X-siglo XI) se caracteriza por el cambio de función del espacio interior de la iglesia, que comienza a ser empleado para el almacenamiento de cereal. Así, se abrieron, tanto en la nave como en el ábside, al menos 35 silos de grandes capacidades (volumen estimado: $x^{\prime}=1019 l$ ). Se desconoce el número total al quedar buena parte de la planta del templo fuera de los límites de la excavación. Como los silos se cortan entre sí, y aunque se extienden por todo el espacio disponible, sabemos que nunca debieron estar abiertos más que unos pocos a la vez, por lo que es perfectamente razonable que el templo mantuviera su función litúrgica. Hay que precisar que durante esta fase tanto el baptisterio como el cementerio exterior siguieron en uso.

A finales del siglo XI o comienzos del siglo XII, ya en la fase 7 (hasta el siglo XIV), se procedió al completo desmantelamiento de la primitiva iglesia, después de más de cinco siglos de actividad, y a la construcción unas décadas después de un nuevo templo más pequeño, bajo la advocación de San Martín, con su necrópolis aneja.

Esta iglesia estaba orientada E-O, dispuso de un ábside semicircular y, probablemente, de una única nave, planta rectangular y reducidas dimensiones. La única hilada conservada en alzado revela que se levantó con mampuestos trabajados, con al menos sus caras de contacto y cara vista regularizadas. Se disponían en hiladas horizontales y en una organización núcleo interno/caras exteriores en la que el núcleo se ejecutaba mediante material local sin trabajar y argamasa. El material empleado fue exclusivamente caliza local, aunque es más que probable que se utilizaran litologías alóctonas para vanos y quizá esquinales.

Llama la atención su emplazamiento. No solo no se aprovechó ningún paramento del templo anterior, sino que además levantaron el nuevo templo a sus pies, lejos de la zona de mayor consideración sacra, su ábside. En principio esto sugeriría que cuando comenzaron a construir San Martín la iglesia primitiva estaba ya arrasada, quedando únicamente en el lugar un recuerdo como espacio sagrado. Ello explicaría también el hiato de medio siglo entre ambas edificaciones.

\subsection{EI despoblado de Torrentejo (Labastida)}

La pequeña ermita de Santa Lucía es el único resto material visible que se conserva de la desaparecida aldea de Torrentejo. Se emplaza a orillas del Ebro y a un kilómetro al noroeste de la villa de Labastida. Entre 2014 y 2016 se llevaron a cabo tres campañas de excavación en el entorno del templo bajo la dirección de J. A. Quirós. Estas afectaron sobre todo al espacio inmediatamente al sur de la iglesia, aunque también se intervinieron varios sectores al norte y noroeste y se realizaron varias trincheras de valoración. El sondeo meridional, así como una lectura estratigráfica de alzados en el lienzo S, permitieron elaborar una secuencia ocupacional (Quirós 2015) de la que mencionaremos las fases 3 y 4 .

La fase 3 (siglos XI-XII) implicó la construcción de un edificio destacado y su posible iglesia asociada. 


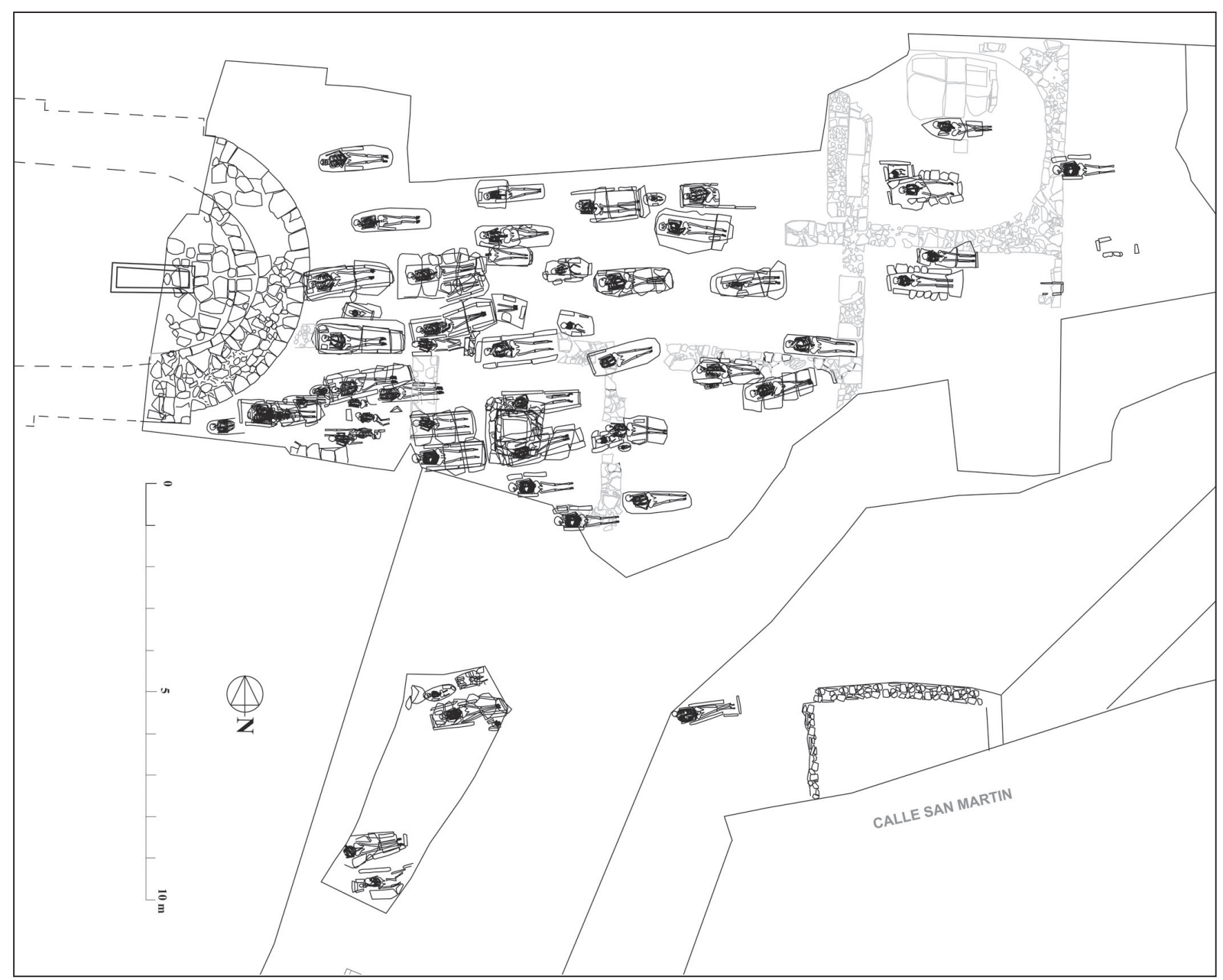

Figura 5. San Martín de Dulantzi. Planta con las dos iglesias y los enterramientos asociados a la segunda (fuente: Iterbide SC).

Esta segunda construcción ha sido interpretada como edificio de culto porque su muro de mampuestos de arenisca miocena orientado NE-SO fue cortado al levantar el templo del siglo XII, manteniéndose en uso hasta que levantaron la cabecera.

En un momento sin precisar del siglo XII, ya durante la fase 4 , se levantó una nueva iglesia con ábside semicircular, presbiterio y una sola nave en dos momentos distintos, aunque próximos entre sí. En la primera etapa se edificó toda la cabecera y parte del extremo oriental de la nave, mientras que en la segunda se continuó la obra hacia el oeste. Esta última solo se ha identificado en el proceso de excavación, por lo que desconocemos si los sillarejos que la componen se emplearon solo para los cimientos o también para el resto de los alzados. Con todo, los paramentos de la primera etapa estaban elaborados con sillares de arenisca miocena dispuestos en hiladas horizontales y con talla diagonal de tallante a $45^{\circ}$. Salvo el amplio lapso del empleo de este útil (Sánchez Zufiaurre 2007: 328-341, Bessac 1986: 51, 104) no disponemos de argumentos materiales para certificar su cronología. Con todo, los historiadores del arte coinciden en considerarla del siglo XII (Cantera 1967: 198-199, Pérez García 1985: 363). No hay evidencias de que la iglesia contara con un espacio funerario asociado.

\subsection{La basílica de San Prudencio de Armentia}

Armentia es una pequeña localidad situada a escasos $3 \mathrm{~km}$ del centro de Vitoria-Gasteiz, a cuyo municipio pertenece. Más allá de su iglesia parroquial, la basílica de San Prudencio, nada recuerda al visitante su notable pasado medieval. De hecho, aquí se estableció la sede del obispado de Álava durante la Alta Edad 


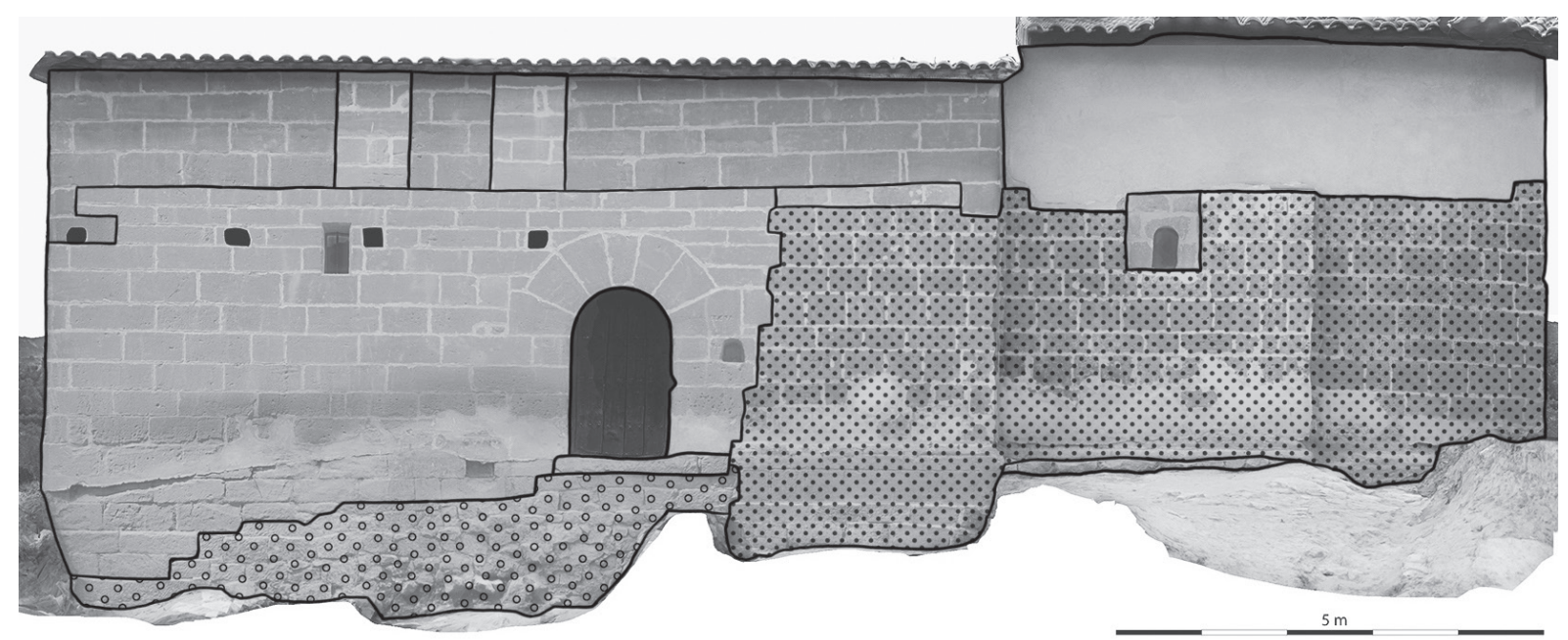

Figura 6. Torrentejo. Fases constructivas de la ermita. Se marcan con puntos los dos momentos de la fase 4 (fuente: Quirós 2015).

Media hasta que en 1087 o 1088 se convirtió en colegiata, estatus que mantendría hasta finales de la Edad Media (Portilla 1991: 218-219).

Bajo la dirección de A. Azkarate se llevó a cabo durante tres años (2003-2005) una intervención arqueológica, que supuso tanto la excavación de la zona circundante a la iglesia como la lectura estratigráfica de sus alzados. Su secuencia ocupacional se dividió en seis periodos y 16 fases, desde el siglo XI al XX (Azkarate et al. 2005), aunque solo nos centraremos en las seis primeras al ser las que se inscriben en la franja temporal de este estudio.

Sobre la amortización de las estructuras domésticas excavadas en la roca que conforman la fase 1 (ante quem siglo XI), se construyó en la fase 2 (siglo $\mathrm{XI})$ una primera iglesia, de la cual solo se ha identificado su esquina noroeste. Se emplearon sillares de caliza paleocena en sus esquinales y mampostería de calizas locales en el resto del muro. Estos exiguos restos no permiten reconocer su planta y dimensiones originales, aunque sí evidencian que mantenía una alineación NO-SE, diferente a la del edificio de culto actual.

Asociados a esta primera iglesia se identificaron varios agujeros de poste, cinco silos y un foso de más de $3 \mathrm{~m}$ de anchura que delimitaba presumiblemente el espacio eclesial. Los silos tenían una planta circular, sección piriforme, 0'83 $\mathrm{m}$ de profundidad máxima conservada y unos promedios en sus diámetros de $1^{\prime} 32 \mathrm{~m}$ en la parte superior, 1'44 $\mathrm{m}$ en la central y $1^{\prime} 17 \mathrm{~m}$ en la inferior. Cuatro de los silos estaban agrupados.
También se han asignado 17 enterramientos y dos fosas vacías a este momento. Sin embargo, no se puede establecer con rotundidad su contemporaneidad debido a la ausencia de relaciones físicas con el templo. Se ubican al este y al sur del mismo y todos ellos están realizados en fosa simple.

La fase 3 (siglo XII) corresponde a la primera fase constructiva de una nueva iglesia, que no fue una obra homogénea y respondió, de hecho, a varios cambios de diseño. Se trata de una iglesia de cruz latina realizada en sillería con acabado a tallante, cimborrio sobre el crucero, presbiterio y cabecera semicircular. Es, por tanto, una obra de cantería en la que participaron únicamente maestros especializados con destacables conocimientos técnicos.

Su cementerio asociado se extendió hacia el norte y sur de la nave, diversificándose las técnicas constructivas de los enterramientos debido a la presencia de rellenos antrópicos que impedían alcanzar la roca natural. De este momento son también varios restos de estructuras en materiales perecederos, así como un silo de almacenaje.

Durante las fases 4, 5 y 6 (siglo XII) continuó la edificación de la iglesia hacia el oeste, adosándose un pórtico al sur. Implicó igualmente una mayor actividad funeraria, extendiéndose la zona de inhumación hacia el espacio utilizado para habitación y almacenaje de la fase anterior. Estas estructuras acabaron amortizándose en la fase siguiente, cuando se construyó el cementerio al nordeste. La fase 5 se caracterizó además por la ampliación del crucero norte. En la fase 6 se levantó un cimborrio flanqueado en sus cuatro esquinas por torreones circulares. 


\section{DISCUSIÓN}

La exposición de las secuencias ocupacionales de estos seis yacimientos alaveses revela la presencia de transformaciones de diverso calado que ocurren, en todos los casos, en una horquilla cronológica precisa: el siglo XII. Estas alteraciones afectaron a la iglesia preexistente en Zaballa, Aistra, Armentia y Torrentejo, al templo y a su entorno inmediato en Dulantzi y a todo el espacio aldeano en Zornoztegi.

Parece que, más allá de sus diversas situaciones de partida, algo ocurrió a lo largo de esta centuria que dejó una impronta en el registro material. Sin embargo, ¿pueden estos cambios ser interpretados como evidencias materiales de la creación y extensión de la red parroquial sobre estas aldeas? Tratemos de responder a esta pregunta confrontando el registro de cada yacimiento agrupado en modelos definidos a partir de la situación preexistente.

\subsection{Aldea sin iglesia}

El despoblado de Zornoztegi caracteriza el primer modelo de análisis: una aldea de origen altomedieval que se dota de su primera iglesia en el siglo XII. Como se ha dicho, la construcción de dicho templo y su necrópolis asociada supuso la sacralización de un espacio doméstico previo, así como la reestructuración del caserío circundante. Pero ¿tenemos evidencias para asociar estas transformaciones con la red parroquial?

Hagamos hincapié sobre dos cuestiones. Por un lado, Santa María rompió de forma drástica con el ambiente técnico (el conjunto de saberes técnicos que desarrollaban las comunidades de tamaño pequeño y medio interactuando con el ambiente externo y cuyo rasgo más característico era la continuidad, v. Bianchi 1996: 53-54) imperante en la aldea desde el comienzo de la Edad Media. Inserto en la tradición constructiva local, se había caracterizado por estructuras domésticas sobre postes y semiexcavadas. La ruptura se infiere de la introducción del ciclo productivo de la piedra y la cal, la sofisticación de la técnica de mampostería, el empleo de materiales líticos alóctonos de gran calidad para elaborar vanos y elementos decorativos, el uso del tallante para la talla y el cierre oriental del templo mediante una cabecera semicircular.

Todo ello indica que, aunque la construcción del templo estuvo liderada por albañiles, contó con rasgos de la tradición especializada: participación de canteros, promotores con recursos, ciclo productivo de la piedra elaborado, división del trabajo, amplios conocimientos técnicos o empleo de piezas talladas nuevas de cantera (Bianchi 1996, Mannoni 1997, Quirós 2001).

Por otro lado, se produjo una reorganización del espacio aldeano, promoviendo una nueva zona litúrgica y funeraria en una posición central y elevada respecto al caserío. Ello supuso además la amortización de estructuras domésticas de prestigio anteriores, en uso desde el siglo X.

Este cambio en la función del espacio aldeano no resulta intrascendente. Antes de este momento y desde la Alta Edad Media, Zornoztegi habría dispuesto probablemente de un espacio funerario en el que enterrar a sus muertos. No obstante, en algún momento del siglo XII se decide olvidar este espacio ancestral (hasta el punto de que no hemos hallado ninguna prueba documental o arqueológica de su existencia) y sacralizar uno nuevo hasta entonces destinado a actividades profanas. Ello debió suponer un enorme cambio simbólico en el mapa mental de la comunidad: la referencia espacial básica de los siglos anteriores, la base de su pasado y de su origen fue sustituida y progresivamente olvidada, en lo que creemos fue un proceso paulatino que se alargó en el tiempo.

En definitiva, se reorganiza el espacio aldeano coincidiendo con la edificación de un templo y su necrópolis sobre un espacio privilegiado de la aldea. Aunque resulte complicado establecer qué sujetos sociales promovieron estas actividades, es obvia su capacidad de movilización de recursos e influencia en el seno de la aldea. No resulta descabellado sugerir, en este punto y atendiendo a lo expuesto, que se tratase de representantes del poder diocesano convergiendo y colaborando con la comunidad aldeana, en especial sus elites, en el contexto de extensión y consolidación de la red parroquial (Alfaro 2018).

\subsection{Aldea con iglesia propia}

Conviene precisar, antes que nada, que como iglesias propias entendemos, siguiendo la tradición historiográfica española y europea (proprietary churches, Eigenkirche), las ecclesiae y monasteria de los diplomas altomedievales. Se caracterizaron por su carácter familiar, con una organización variable y poco definida, y privado. Sus dueños, que pudieron ser laicos (familias nobiliarias o monarquía) o religiosos (monasterios u órdenes militares), las fundaban con tres tipos de 
intereses: espirituales, para lograr la salvación de sus almas, económicos, para cohesionar, aumentar y asegurar su patrimonio; $\mathrm{y}$ de prestigio y estatus, como instrumento de diferenciación social y de perpetuación de la memoria. Asimismo, las donaban, compraban y enajenaban como cualquier otra propiedad (Fernández Conde 2000: 276-277, Wood 2006: 445, Davies 2007: 215-216, Pérez 2012).

Dentro de este segundo modelo incluiremos los despoblados de Aistra y Zaballa, así como el yacimiento de San Martín de Dulantzi. Aunque cada uno cuente con sus peculiaridades, los tres tienen unos puntos de partida y siguen desarrollos evolutivos similares. Se trata de aldeas que dispusieron de iglesias propias al menos desde el siglo X y que, en torno al siglo XII, sufrieron alteraciones de diverso calado.

En el caso de Zaballa la condición de iglesia propia se justifica materialmente por la gran reorganización del espacio que acontece en la aldea coincidiendo con su construcción, que implica tanto la movilización de toda la población hacia el valle, como la sacralización del espacio central, quizá primigenio, de la aldea. Recordemos que estas transformaciones tuvieron lugar en Zornoztegi dos siglos después. En ambos casos lo vinculamos a la entrada en escena de poderes extralocales, aunque de diferente naturaleza: el obispado en Zornoztegi, una familia noble de influencia regional en Zaballa. La diferencia de interpretación entre ambos la fundamentamos en el conocimiento que, gracias a las fuentes escritas, tenemos tanto de la debilidad de las diócesis como de la proliferación de iglesias propias de carácter familiar a lo largo del siglo X (Quirós y Santos 2015, Alfaro et al. 2017: 266-267).

Ciertamente, la única actividad del registro material fechable en el siglo XII de la aldea de Zaballa, el añadido de un pórtico, tiene una entidad e importancia más limitada que en Zornoztegi. Sin embargo, no debemos desmerecer las implicaciones de esta nueva estructura. Hay que tener en cuenta que los pórticos otorgan cierto carácter comunitario al uso de las iglesias. Crean un espacio cubierto donde los habitantes de la aldea podían esperar a la celebración de los oficios y, por consiguiente, hablar, discutir y decidir sobre asuntos diversos (Bango 1975, Curiel 2009: 147). Todo ello en consonancia con lo que se espera de una iglesia parroquial, por lo que es posible que de la construcción de este elemento se infiera la presencia de la parroquia en la aldea.

Dicha interpretación estaría avalada además por la continuidad del cementerio al menos hasta el siglo XIII y por la mención de la iglesia de Zaballa entre las propiedades del obispo en la concordia de 1257, donde prelado y cabildo catedralicio se repartían las rentas de los templos pertenecientes a la diócesis de Calahorra (Rodríguez y Rodríguez de Lama 1989: 216-234).

Resulta plausible, además, que la construcción del pórtico estuviera acompañada de una reforma o ampliación de la antigua iglesia propia, en consonancia con lo que se conoce de otros templos alaveses erigidos antes del siglo XII (Sánchez Zufiaurre 2007). Sin embargo y dado que solo se han conservado los cimientos de la iglesia, es probable que las huellas de estas posibles modificaciones arquitectónicas sencillamente no hayan llegado hasta nosotros.

La naturaleza privada de la iglesia construida en Aistra en el siglo X se argumenta también a partir de los profundos cambios en la organización espacial de la aldea que generó y de la total ruptura de la obra eclesial con el ambiente técnico anterior. Ambos hechos nos orientan a promotores de ámbito supralocal con amplios recursos.

De hecho, las características constructivas de la iglesia primitiva de San Julián y Santa Basilisa (bloques nuevos de cantera, empleo de litologías alóctonas de difícil talla, puesta en obra ordenada y predecible, piezas decorativas, etc.) describen con claridad un sistema productivo de cantería liderado por maestros especializados.

Las transformaciones que paralelamente se desarrollaron en el espacio aldeano, sin embargo, son equiparables a las comentadas para Zaballa y, en otro contexto y cronología, para Zornoztegi. Aunque hay importantes diferencias a destacar: la iglesia se construyó en un lugar aparentemente periférico de la aldea, vacío hasta ese momento, y supuso el abandono de parte del espacio doméstico y funerario altomedieval.

Al igual que en Zaballa, en Aistra solo contamos con las modificaciones que sufrió el templo en el siglo XII para sugerir la presencia de la institución parroquial. La reforma de la iglesia en este momento evidencia un cambio claro en sus promotores y funcionalidad. Así, el primitivo templo se reconstruyó probablemente después de haberse arruinado casi del todo, quizá por la desidia de sus propietarios, que ya no contaban con los incentivos que habían llevado a aquellos promotores del siglo $\mathrm{X}$ a erigir una iglesia propia en esta aldea alavesa.

El sistema productivo mixto de la reforma, en el que se emplea sobre todo material reutilizado con una participación puntual de canteros, reflejaría una menor capacidad de movilización de recursos por parte de los promotores. Edificaron una iglesia funcional y 
bien ejecutada con una inversión mínima. De ello se infiere que fue probablemente la confluencia entre los representantes del poder episcopal y la comunidad aldeana, ya anunciada en el caso de Zornoztegi, la que se hizo con esta vieja iglesia arruinada y decidió reformarla para que cumpliera sus nuevas funciones como iglesia parroquial.

San Martín de Dulantzi difiere en tres destacables aspectos de los dos casos mencionados hasta ahora en este modelo de análisis. Primero, no hay continuidad física y espacial entre la iglesia propia y la que se edifica en el siglo XII. Segundo, el primer templo se construyó cuatro siglos antes de que podamos sugerir con una mínima seguridad su naturaleza privada. Tercero, la iglesia propia dispuso de un baptisterio que le otorgaba más competencias que en Zornoztegi o Zaballa. En cualquier caso, y a pesar de sus divergencias, mantiene en lo fundamental la misma evolución observada en estos dos casos de estudio.

La utilización a partir de la segunda mitad del siglo X del interior del templo para el almacenamiento de cereal es un indicador, a nuestro entender, de que ya se encontraba bajo control privado. Como ocurrió en Zaballa y Aistra, parece que elites de importancia y ámbito regional comenzaron a controlar una iglesia, en este caso una preexistente, con intereses espirituales y, claro está, terrenales.

Ello vincularía la apertura de las grandes estructuras de almacenaje en el interior con la percepción de rentas eclesiásticas, probablemente, y viendo su elevado número para los dos siglos posteriores, sobre un ámbito territorial mayor que en Zaballa.

Su condición de iglesia propia no implicó el cese de los servicios sacramentales que ofrecía a la comunidad, puesto que continuaron empleándose el baptisterio y el espacio circundante como lugar de enterramiento de la comunidad.

Estas competencias sobre la cura de almas, así como la centralidad referencial y simbólica que la iglesia debió tener para los habitantes de la aldea, debieron funcionar además como instrumentos para legitimar la autoridad de percibir sus diezmos (Alfaro et al. 2017).

A diferencia de los casos de Zaballa o Aistra, en este yacimiento la iglesia propia se desmanteló completamente a finales del siglo XI o comienzos del XII, después de más de cinco siglos de actividad, construyéndose el nuevo templo de San Martín sobre un depósito de nivelación unas décadas después.

Este hiato, en el que presumiblemente los habitantes de Dulantzi no dispusieron de un templo al que acudir para recibir sus sacramentos, subraya el carácter privado del mismo en su etapa anterior. Es cierto que había tenido competencias comunitarias, como la administración de sacramentos o la percepción de rentas eclesiásticas, pero fue ante todo una iglesia propia. Cuando los poderes que la habían instrumentalizado desaparecieron o dejaron de necesitarla, bien porque ya no era rentable, bien porque cambiaron las formas de representación del poder, la iglesia acabó arruinándose.

El lapso entre ruina y construcción recuerda al caso de San Julián y Santa Basilisa de Aistra, cuya reforma del siglo XII se ejecutó sobre las ruinas del templo anterior, aunque en Dulantzi ni siquiera aprovecharon alguno de los paramentos que todavía estaban en pie. Nivelaron el terreno y construyeron San Martín a los pies de la iglesia tardoantigua. Una tabula rasa que llama poderosamente la atención porque se obviaron, quizá al haber pasado suficiente tiempo para que fueran olvidados, los elementos en teoría más sagrados como la cabecera y su enterramiento privilegiado.

Todos estos indicadores aluden a un profundo cambio de promotores y funciones, probablemente con el escenario de la implantación de la red parroquial como telón de fondo. Suponemos que el estado en que se encontraba el viejo templo, además de su gran tamaño, poco apropiado para las modestas necesidades de una parroquia aldeana, hicieron desechar a los nuevos promotores la idea de una reconstrucción siquiera parcial.

\subsection{Aldea con iglesia episcopal}

Armentia representa un caso inédito en la muestra, al ser una antigua sede episcopal y constatarse documentalmente un precoz control por parte de la diócesis de Calahorra, tras el establecimiento efectivo del arcedianato de Álava en 1135 (Rodríguez y Rodríguez de Lama 1992: 178-179).

De la fase vinculada a priori con la sede del obispado de Álava contamos solo con estructuras domésticas de habitación. Llama la atención que no se hayan identificado ni la iglesia ni un espacio cementerial asociado. ¿Dónde estaba el templo episcopal? ¿Dónde se enterraban los habitantes de la aldea? Desde luego no en este lugar, ocupado en aquel momento por contextos domésticos.

Se desconoce además el momento exacto de construcción de la primera iglesia, pudiendo ser anterior al desmantelamiento del obispado en 1087-1088, así como la naturaleza de los promotores que la impulsaron. Después de todo, si la obra es anterior a esta fecha, 
debió de tratarse de la propia diócesis de Armentia; pero si es posterior no debe descartarse la participación de otro tipo de poderes en su construcción.

Tampoco sabemos con certeza si a su alrededor congregó un cementerio, ya que los enterramientos adscritos no disponen de relaciones estratigráficas que confirmen este punto. Con todo, los cuatro silos agrupados y contemporáneos a este templo sugieren la apropiación de rentas eclesiásticas ya desde el siglo XI.

La iglesia del siglo XII, por su parte, se caracteriza por sus grandes dimensiones, además de por su excelente factura, planta de cruz latina, ábside semicircular y cimborrio sobre el crucero (este tipo de planta es por sí mismo un rasgo de la excepcionalidad y significación de la iglesia de Armentia. Salvo Nuestra Señora de Estíbaliz, todas las iglesias conservadas de esta época en Álava tenían planta rectangular). Todas estas características nos remiten a una obra de canteros con destacados conocimientos técnicos, de elevados costes y con importantes promotores detrás. Es muy probable que haya que identificarla con el documento de 1135, donde se menciona la concesión a Armentia de las cuartas episcopales de veinte iglesias del entorno (Rodríguez y Rodríguez de Lama 1992: 178-179).

En definitiva, resulta factible que, debido al control episcopal directo del enclave de Armentia, ya desde el siglo XI su iglesia actuara a modo de parroquia. Al fin y al cabo, se percibían rentas eclesiásticas y era posiblemente un lugar de enterramiento y de administración de sacramentos para la comunidad.

Asimismo, la edificación del siglo XII hay que ponerla en relación con el esfuerzo del obispado de Calahorra, materializado en el documento de 1135, para reforzar la posición de Armentia como cabecera del arcedianato de Álava. Por ello, le fue entregado al arcediano una casa, heredades y las rentas (cuartas episcopales) de veinte iglesias próximas. El apoyo de Calahorra y las rentas obtenidas permitieron financiar los elevados costes del nuevo templo, contratando mano de obra especializada. Del cementerio asociado se infiere que, si la iglesia de Armentia no había dispuesto de funciones parroquiales desde el siglo XI, las desarrolló con seguridad a partir de este momento.

\subsection{Aldea con iglesia monasterial}

Conviene explicar en este punto que empleamos el término iglesia monasterial para aludir a las iglesias instaladas dentro del complejo de un monasterio sub regula, y no a las iglesias que eran propiedad de un monasterio.
El despoblado de Torrentejo es también singular, aunque por motivos diferentes a los de Armentia. Tanto la ausencia de un cementerio comunitario en su entorno, como que su iglesia no fuera mencionada en la referida concordia de 1257 (No obstante, esta ausencia pudo deberse a otras razones. Resulta llamativo que ni Labastida, ni otras poblaciones del oeste de la Rioja Alavesa que pertenecían al arcedianato de Nájera se citen en el documento. Por ello y dado que se desconocen los motivos que se esconden tras estas ausencias, sugerimos obrar con prudencia en este punto.), parecen sugerir que no desarrolló nunca un estatus parroquial.

De aceptar dicha interpretación surge una pregunta ineludible: ¿quién estuvo detrás de la iglesia del siglo XII, edificada con un sistema productivo de cantería por artesanos especializados y una elevada inversión?

Dado que un documento de 1075 menciona la donación de la iglesia de «Santa María de Torrencillo» por parte del rey Sancho IV de Pamplona a San Millán de la Cogolla, es probable que perteneciera a este monasterio. No obstante, este diploma está transcrito en el Becerro Galicano, redactado a finales del siglo XII, que consta con un encabezado en el que se hace referencia al monasterio de Santa María de Torrentejo (Becerro Galicano Digital [doc. 597]). Ello podría señalar la existencia de un complejo monasterial en este lugar para el siglo XII o su condición de decania sujeta a San Millán.

Torrentejo mantiene cuatro relevantes diferencias con el resto de casos de estudio. En primer lugar, es el único en el que no es posible vincular la reforma/construcción de la iglesia en el siglo XII con la parroquia. Obliga, por tanto, a cuestionar una relación directa tentadora, aunque reduccionista, entre ambos fenómenos.

Igualmente, a pesar de que los templos del siglo XI y del siglo XII son edificios distintos, no existe, como en Aistra o Dulantzi, un hiato más o menos destacado entre la destrucción y la reforma/construcción, sino que hay una aparente continuidad entre ambos. Quizá refleje la permanencia de su vínculo con poderes no diocesanos.

En tercer lugar, el edificio de culto del siglo XII es, junto al excepcional caso de Armentia, el único donde se infiere una participación exclusiva de la figura del cantero. Recordemos que en Zornoztegi, Aistra y Dulantzi fueron obras mixtas con una inversión más limitada.

Finalmente, el presbiterio de la iglesia del siglo XII llama la atención por sus dimensiones: 4'7 m entre sus paredes interiores norte y sur (medida A) y $4 \mathrm{~m}$ entre el arco toral, que separa el ábside del presbiterio, y el arco triunfal, que hace lo propio con el presbiterio y la nave 


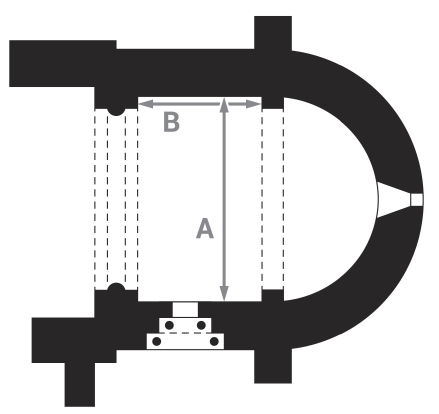

\begin{tabular}{|c|c|c|c|c|c|}
\hline LOCALIDAD & MUNICIPIO & ADVOCACIÓN & ESTATUS & $\begin{array}{c}\text { MEDIDA } \\
\text { A (m) }\end{array}$ & $\begin{array}{c}\text { MEDIDA } \\
\text { B (m) }\end{array}$ \\
\hline Acebedo & Valdegovia & San Juan Evangelista & Parroquia & 3,2 & - \\
\hline Alaitza & Iruraiz-Gauna & Nuestra Señora de la Asunción & Parroquia & 4,1 & 2,7 \\
\hline Alegría-Dulantzi & Alegría-Dulantzi & Nuestra Señora de Ayala & Ermita & 4,9 & 2,4 \\
\hline Argandoña & Vitoria-Gasteiz & Santa Columba & Parroquia & 4,6 & 2,0 \\
\hline Armentia & Vitoria-Gasteiz & San Prudencio & Parroquia & 6,4 & 4,2 \\
\hline Aturi & Arraia-Maeztu & La Soledad & Ermita & 3,3 & 1,0 \\
\hline Bellojín & Valdegovía & San Cornelio & Parroquia & 3,9 & 2,1 \\
\hline Berantevilla & Berantevilla & Santa María de Tobera & Ermita & 4,4 & 3,9 \\
\hline Elburgo & Elburgo & San Juan de Arrarain & Ermita & 6,6 & 2,4 \\
\hline Gazeo & Iruraiz-Gauna & San Martín de Tours & Parroquia & 4,0 & 2,5 \\
\hline Hueto Arriba & Vitoria-Gasteiz & La Natividad & Parroquia & 5,5 & 3,8 \\
\hline Karkamu & Valdegovía & San Juan Bautista & Ermita & 3,8 & 1,7 \\
\hline Kontrasta & Valle de Arana & Nuestra Sra. de Elizmendi & Ermita & 2,1 & 2,2 \\
\hline Labastida & Labastida & Santa Lucía & Ermita & 4,7 & 4,0 \\
\hline Markinez & Bernedo & San Juan Bautista & Ermita & 4,7 & 3,3 \\
\hline Nanclares de la Oca & Iruña Oca & La Asunción de Ntra. Sra. & Parroquia & 6,8 & - \\
\hline San Vicentejo & Treviño & La Concepción & Ermita & 5,6 & 1,8 \\
\hline Sobrón & Lantarón & San Martín de Lantarón & Ermita & 3,1 & 1,9 \\
\hline Trokoniz & Iruraiz-Gauna & San Vicente & Parroquia & 4,4 & - \\
\hline Ullíbarri-Arana & Valle de Arana & Andra Mari & Ermita & 3,6 & 1,9 \\
\hline Valluerca & Valdegovia & Santa María & Parroquia & 3,6 & 2,4 \\
\hline
\end{tabular}

Figura 7. Tabla con las dimensiones del presbiterio de aquellas iglesias de los siglos XII-XIII de Álava con ábside semicircular y planta publicada. 
(medida B). A modo de referencia, la referida iglesia de Zornoztegi, también del siglo XII y con cabecera semicircular, cuenta con un tamaño más reducido: 3'5 m en la medida A y 1'2 m en la B.

Podría plantearse, dada la probable condición monasterial de Santa María en el siglo XII, que este gran presbiterio respondiera a una mayor necesidad de espacio del clero regular, que habría atendido los oficios en este lugar, dejando la nave para una posible feligresía laica.

Si lo comparamos con los de otras iglesias de Álava y Treviño con ábsides semicirculares y datadas en los siglos XII-XIII (siempre con la debida cautela dadas las diferencias socioeconómicas entre sus diferentes regiones), vemos que destaca sobre el resto. Si bien su anchura (medida A) es convencional ( 4’4 m), con hasta seis iglesias (de una muestra de 20) con valores superiores, la longitud de su presbiterio (medida B) es la segunda más amplia y 1'5 $\mathrm{m}$ superior al promedio (2'5 m). Igualmente, el espacio útil del presbiterio es el tercero más grande $\left(11^{\prime} 7 \mathrm{~m}^{2}\right)$ con $20^{\prime} 9 \mathrm{~m}^{2}$.

A pesar de que efectivamente el de Santa María es un presbiterio de grandes dimensiones, no consideramos plausible explicar dicha circunstancia a través de su naturaleza monacal por dos razones: la ermita de Nuestra Señora de Elizmendi en Kontrasta, también de origen monasterial, contó con un presbiterio mucho más reducido (4' $6 \mathrm{~m}^{2}$ de área útil) y las iglesias que tienen presbiterios más grandes, la de Armentia y la de Hueto Arriba, parecen estar asociadas a otros poderes, diocesanos o locales-comunitarios.

\subsection{Valoración: diversidad de marcadores materiales}

En definitiva, parece que, salvo en el caso de Torrentejo, es posible relacionar las transformaciones materiales ocurridas durante el siglo XII con la extensión de la red parroquial. Llama la atención, sin embargo, la variedad de marcadores para tan solo seis casos de estudio, que refleja la complejidad del fenómeno y los diversos itinerarios que debieron seguirse en función de las situaciones de partida.

Entre estos marcadores materiales el más destacado es la presencia de un pórtico cubriendo el acceso principal a la iglesia. Que no haya sido identificado en iglesias propias o monasteriales, así como su presencia en las iglesias del siglo XII de Zornoztegi, Zaballa y Armentia parecen aludir a una naturaleza parroquial. También el hecho, ya comentado, de que este elemento otorgue un carácter comunitario al templo, al ofrecer un lugar a la comunidad para poder desarrollar diferentes actividades, refuerza esta idea.

La reforma arquitectónica de la iglesia siguiendo un modelo productivo mixto, en el que colaborasen canteros y albañiles, se emplea también como marcador de la parroquia, al reflejar promotores y funciones diferentes a los de las iglesias propias (Alfaro 2017). Por otra parte, una ruina total o parcial del templo, seguida de un hiato previo a su reconstrucción es, bajo nuestro punto de vista, un marcador aún más consistente. El caso de Dulantzi es significativo, más cuando hay una diferenciación física bien marcada entre el templo y el cementerio del siglo VI y los del siglo XII. Es probable que en Aistra hallemos un caso similar, aunque reconstruyendo la iglesia anterior.

Se han utilizado también otros marcadores materiales menos concluyentes que parecen asociarse igualmente a otro tipo de procesos y realidades, y que es necesario considerar en función del contexto y la cronología. Nos referimos a la reorganización del espacio aldeano o la presencia de caracteres constructivos que impliquen la ruptura con el ambiente técnico previo. Como hemos visto en los casos de Zornoztegi, Zaballa y Aistra, actúan más bien de indicadores de la introducción en el contexto aldeano de poderes extralocales, que pudieron ser familias propietarias de variada influencia, grandes cenobios o autoridades episcopales.

Para concluir, ni la función funeraria abierta a la comunidad, ni la apropiación de rentas eclesiásticas son marcadores fiables de este proceso, al menos para el caso alavés, ya que los hemos hallado indistintamente asociados a iglesias propias.

Así, la función funeraria se reconoce en Zaballa y Aistra desde el siglo X y en Dulantzi desde el siglo VI (aunque generalizada a toda la comunidad desde el siglo VIII). Los tres casos mantuvieron el espacio de enterramiento tras su conversión en parroquia en el siglo XII.

La historiografía ha tendido en este punto a poner el acento en las diferencias tipológicas entre enterramientos para discriminar cementerios de diferentes categorías. En este sentido, I. García Camino plantea para la cercana región de Vizcaya cómo los cementerios parroquiales, que fueron reemplazando a los altomedievales desde los siglos XI y XII, se caracterizan por una homogeneización de las prácticas funerarias. Asocia esta mayor uniformidad al triunfo de los planteamientos funerarios cristianos que niegan la personalidad del difunto y la individualidad de la tumba. Dichos cementerios se definían además por 
las sepulturas de lajas, la ausencia de ajuares y, fundamentalmente, la reutilización de tumbas (García Camino 2002: 250-252).

Esta misma dicotomía entre cementerios parroquiales y anteriores, con una mayor variedad tipológica de las sepulturas, fue identificada en el yacimiento guipuzcoano de Santa María de Zarautz. El paso entre uno y otro se habría producido también durante los siglos XI y XII (Ibáñez y Moraza 2006: 432).

Sin embargo, ya solo el caso de Aistra genera dos notables discordancias con este modelo: la temprana cronología y las reutilizaciones. Sobre la primera, I. García Camino menciona la extensión de este tipo de cementerios desde el siglo XI, pero la construcción de la iglesia de Aistra y su necrópolis datan del siglo X. Por otro lado, la reutilización de las sepulturas es para el arqueólogo vizcaíno la característica principal de los cementerios parroquiales y, en Aistra, aunque de forma minoritaria, la encontramos.

Quizá la solución a este aspecto radique en incidir no en el propio hecho de la reutilización, sino en su intensidad, como proponía E. Gutiérrez Cuenca en su tesis doctoral sobre las necrópolis de Cantabria en la Edad Media. El autor apuntaba que, mientras que esta práctica fue poco frecuente en los «cementerios altomedievales» (siglos VIII-XIII), el paso de un modelo de cementerio extensivo a uno intensivo multiplicó las reutilizaciones en los «cementerios bajomedievales/parroquiales» (siglos XIII-XV) (Gutiérrez Cuenca 2015: 640, 644).

Por su parte, los silos de almacenaje, que evidencian la apropiación de rentas eclesiásticas, tampoco son un marcador fiable para el reconocimiento de la parroquia. No solo porque se identifiquen en las iglesias propias de Zaballa o Dulantzi, sino también porque, salvo Armentia con su silo amortizado relativamente pronto en el siglo XII, ninguna de las interpretadas como parroquiales disponía de ellos.

De hecho, resulta significativo que apenas encontremos estas estructuras en contextos eclesiales a partir del siglo XII. Los casos de Zornoztegi, Zaballa, Dulantzi y Armentia parecen sugerir que, durante esta centuria, y a pesar de su uso más o menos generalizado en los siglos anteriores, el método de almacenaje del silo excavado en el subsuelo entró en declive. Es probable que de forma paralela se difundiera el uso de otro tipo de construcciones en alzado como graneros u hórreos, quizá conocidos con anterioridad y cuya identificación material es siempre más problemática.

En este sentido, los pocos silos asociados a iglesias identificados en Álava, apenas una veintena
(Alfaro et al. 2017: 267) parecen indicar que estas construcciones ya se empleaban antes del siglo XII. En esta dirección podrían interpretarse las estancias lignarias anejas a las iglesias del grupo 4 (siglo X-XII) que L. Sánchez Zufiaurre identificó, a partir de ménsulas en los muros $\mathrm{N}$ y $\mathrm{O}$, en su tesis doctoral sobre las iglesias prerrománicas de Álava (Sánchez Zufiaurre 2007: 291, 328).

\section{CONCLUSIONES}

A lo largo de estas páginas se ha dado respuesta a las dos preguntas planteadas en la introducción. Por un lado, es posible identificar transformaciones en el registro material de las aldeas alavesas dentro de una horquilla cronológica bastante específica: el siglo XII. Por otro, es razonable asociar dichas transformaciones con la implantación de la red parroquial en Álava.

No parece, eso sí, que la parroquia de los arqueólogos se corresponda plenamente con la de los historiadores. La diversidad de marcadores materiales reconocida, resultado de la propia variedad de situaciones preexistentes (aldea sin iglesia, aldea con iglesia propia, aldea con iglesia episcopal y aldea con iglesia monasterial), parece reflejar un proceso de establecimiento de la red parroquial más heterogéneo de lo que sugieren las fuentes escritas. ¿Se trató de un largo periodo de transición previo a las uniformes parroquias de la documentación? O, quizá, ¿debemos referirnos más bien a una implantación de las parroquias, en plural, para ilustrar la complejidad de una institución que adoptó rasgos diferenciados en función del momento, la geografía y la naturaleza de los poderes con que debía lidiar?

Todavía no contamos con evidencias suficientes para dar una respuesta concluyente, si es que la hay, a estas cuestiones. Quedan para investigaciones futuras. Baste este trabajo para reconocer el potencial de la praxis arqueológica en la comprensión del proceso de formación de la red parroquial. Como ya señaló E. Zadora-Rio, las contradicciones de los registros documental y arqueológico no son más que aparentes. Sus diferentes explicaciones ni son exclusivas, ni se pueden oponer como si perteneciesen a la misma escala (Zadora-Rio 2008: 265-266). Proponemos, en suma, una visión alternativa y complementaria a la de las fuentes escritas, una visión más de abajo hacia arriba, que aclara aspectos diferentes del universo empírico y centrada en las transformaciones de la identidad aldeana que se infieren de los cambios en el templo, el cementerio y los espacios domésticos. 


\section{Agradecimientos}

Este texto presenta algunas de las ideas desarrolladas en la tesis doctoral defendida por el autor en enero de 2016 en la Universidad del País Vasco UPV/EHU bajo el título La formación de la red parroquial en Álava y Treviño. Evidencias desde la arqueología (siglos XI-XIII).

Este trabajo ha sido realizado gracias a la ayuda para la especialización de personal investigador doctor 2017 del Vicerrectorado de Investigación de la Universidad del País Vasco UPV/EHU. El autor desea agradecer a Javier Niso y Miguel Loza (Iterbide SC) la cesión desinteresada de documentación e información sobre San Martín de Dulantzi, así como a Juan Antonio Quirós, Álvaro Carvajal, Rafael Varón (Universidad del País Vasco) y Javier Ordoño (ARKIKUS) sus aportaciones en la mejora del texto.

\section{BIBLIOGRAFÍA}

Alfaro, E. (2016): La formación de la red parroquial en Álava y Treviño. Evidencias desde la arqueología (siglos XI-XIII). Tesis doctoral, Universidad del País Vasco/Euskal Herriko Unibertsitatea. Inédita.

Alfaro, E. (2017): "La arquitectura eclesiástica en Álava y Treviño durante los siglos XII-XIII: promotores, constructores y significados en un momento de transición". Arqueología de la Arquitectura 14: e056, doi: <https://doi.org/10.3989/arq. arqt.2017.010>.

Alfaro, E. (2019): "Consideraciones en torno a Santa María de Zornoztegi: ¿una parroquia del siglo XII?", en J. A. Quirós (ed.), Arqueología de una comunidad campesina medieval: Zornoztegi (Álava): 441-452. Bilbao, Universidad del País Vasco.

Alfaro, E.; Loza, M.; Niso, J. y Solaun, J. L. (2017): "Iglesias, rentas y sistemas de almacenamiento en el País Vasco durante los siglos X y XI d. C.: el testimonio arqueológico de San Martín de Dulantzi (Alegría-Dulantzi, Álava)". Archivo Español de Arqueología 90: 247-270, doi: <https://doi. org/10.3989/aespa.090.017.011>.

Asenjo, M. (1999): Espacio y sociedad en la Soria medieval. Siglos XIII-XV. Soria, Diputación de Soria.

Azkarate, A.; De la Fuente Arana, A. y Lasagabaster, J. I. (2005): Plan Director de intervención para la restitución de los valores históricos y simbólicos de la Basílica de San Prudencio de Armentia y su entorno. Grupo de Investigación en
Arqueología de la Arquitectura de la Universidad del País Vasco. < http://www.arqueologiadelaarquitectura.com $>$ (descargado 12 de marzo de 2007).

Bango, I. G. (1975): “Atrio y pórtico en el Románico español: concepto y finalidad cívico-litúrgica”. Boletín del Seminario de Estudios de Arte y Arqueología 40-41: 175-188.

Becerro Galicano Digital [doc. 597]: "De monasterio Sancte Marie de Torrentelio, iuxta Iberum". Edición on line, Universidad del País Vasco. <http:// www.ehu.eus/galicano/id597> (consultado 13 de septiembre de 2018).

Bessac, J. C. (1986): L'outillage traditionnel du tailleur de pierre. De l'Antiquité à nos jours. Revue archéologique de Narbonnaise. Supplément 14. Paris, Editions du CNRS.

Bianchi, G. (1996): "Trasmissione dei saperi tecnici e analisi dei procedimenti costruttivi”. Archeologia dell'Architettura 1: 53-64.

Caballero, L. (2001): “Aportación a la arquitectura medieval española. Definición de un grupo de iglesias castellanas, riojanas y vascas", en Actas del V Congreso de Arqueología Medieval Española: 221-235. Valladolid (1999), Valladolid, Junta de Castilla y León.

Caballero, L. y Utrero, M. A. (2005): "Una aproximación a las técnicas constructivas de la Alta Edad Media en la Península Ibérica. Entre visigodos y omeyas". Arqueología de la Arquitectura 4: 169-192.

Calleja, M. (2000): La formación de la red parroquial de la Diócesis de Oviedo en la Edad Media. Oviedo, Real Instituto de Estudios Asturianos.

Cantera, J. (1967): "Labastida y Salinillas de Buradón”, en E. Enciso, J. Cantera, F. Peralta y A. Peña (eds.), Catalógo Monumental de la Diócesis de Vitoria, Tomo I: Rioja alavesa: 189-250. Vitoria, Caja de Ahorros Municipal de Vitoria.

Curiel, I. (2009): La parroquia en el País Vasco-cantábrico durante la Baja Edad Media (c. 1350-1530). Organización eclesiástica, poder señorial, territorio y sociedad. Bilbao, Universidad del País Vasco.

Davies, W. (2007): Acts of Giving. Individual, Community, and Church in Tenth-century

Christian Spain. Oxford, Oxford University Press.

Etxezarraga, I. (2011): "Parroquia, hábitat y comunidad en Guipúzcoa. Una propuesta para el estudio de sus relaciones entre los siglos XIII y XV'. Domitia 12: 89-112.

Fernández Conde, F. J. (2000): La religiosidad medieval en España. Alta Edad Media (siglos VII-X). Oviedo, Trea. 
García Camino, I. (2002): Arqueología y poblamiento en Bizkaia, siglos VI-XII: la configuración de la sociedad feudal. Bilbao, Diputación Foral de Bizkaia.

García de Cortázar, J. A. (1988): La sociedad rural en la España medieval. Madrid, Siglo XXI.

García-Collado, M. I. (2011): Espacios cementeriales en la Alta Edad Media: Álava, siglos VIII-XI. Una lectura social. Memoria fin de máster, Universidad del País Vasco/Euskal Herriko Unibertsitatea. Inédita.

García Retes, E. (1987): “El camino de San Adrián (Guipúzcoa-Álava) en la Ruta Jacobea. Análisis documental y arqueológico". Estudios de Arqueología Alavesa 15: 355-497.

Gutiérrez Cuenca, E. (2015): Génesis y evolución del cementerio medieval en Cantabria. Tesis doctoral, Universidad de Cantabria. $<$ https://repositorio.unican.es/xmlui/handle/10902/7410?show=full $>$.

Ibáñez, A. y Moraza, A. (2006): "Evolución cronotipológica de las inhumaciones medievales en el Cantábrico Oriental: el caso de Santa María la Real de Zarautz (Gipuzkoa)". Munibe (Antropologia-Arkeologia) 57: 419-434.

Lauwers, M. (2005): "Paroisse, paroissiens et territoire. Remarques sur parochia dans les textes latins du Moyen Âge". Médiévales 49: 11-32.

Le Bras, G. (1975): "Historia de la Iglesia", en A. Fliche y V. Martín (eds.), La Iglesia medieval, vol. XII. Valencia, Edicep.

López Alsina, F. (1999): “Parroquias y diócesis: el obispado de Santiago de Compostela", en J. Á. García de Cortázar (ed.), Del Cantábrico al Duero. Trece estudios sobre organización social del espacio en los s. VIII al XIII: 263-312. Santander, Universidad de Cantabria.

López Alsina, F. (2006): “La reforma eclesiástica y la generalización de un modelo de parroquia actualizado", en Actas de la XXXII Semana de Estudios Medievales de Estella: 421-450. Estella (2005), Pamplona, Gobierno de Navarra.

Loza, M. y Niso, J. (2016): "La basílica tardoantigua de San Martín de Dulantzi (Alegría-Dulantzi, Álava)". Pyrenae 47.2: 95-129.

Mannoni, T. (1997): "Il problema complesso delle murature storiche in pietra. 1. Cultura materiale e cronotipologia". Archeologia dell'Architettura 2: 15-24.

Martí, R. (2006): "Del fundus a la parrochia. Transformaciones del poblamiento rural en Cataluña durante la transición medieval", en Ph. Sénac (ed.), De la Tarraconaise à la Marche Supérieure d'al-Andalus
(IV-XI siècle). Les habitats ruraux: 145-166. Toulouse, FRAMESPA.

Mendizabal, A. (2011): "Estudio Antropológico y Patológico de Cementerios Altomedievales en el País Vasco. Los casos del despoblado de Aistra y el Castillo de Treviño". Munibe (Antropologia-Arkeologia) 62: 403-421.

Mendizabal, A. (2013): “Análisis del material antropológico de la necrópolis de Zornoztegi (Álava)”, en J. A. Quirós (ed.), Arqueología de una comunidad campesina medieval: Zornoztegi (Álava). Bilbao, Universidad del País Vasco, en prensa.

Pérez, M. (2012): "El control de lo sagrado como instrumento de poder: los monasterios particulares de la aristocracia altomedieval leonesa". Anuario de Estudios Medievales 42.2: 799-822.

Pérez García, J. M. (1985): La M. N. y M. L. villa de Labastida. Vitoria-Gasteiz, Ayuntamiento de Labastida.

Portilla, M. J. (1991): Una ruta europea por Álava a Compostela. Del paso de San Adrián al Ebro. Vitoria-Gasteiz, Diputación Foral de Álava.

Quirós, J. A. (2001): "La sillería en la arquitectura altomedieval en el Mediterráneo occidental", en Actas del V Congreso de Arqueología Medieval Española: 281-291. Valladolid (1999), Valladolid, Junta de Castilla y León.

Quirós, J. A. (2011): "Las iglesias altomedievales en el País Vasco. Del monumento al paisaje". Studia Historica. Historia Medieval 29: 175-205.

Quirós, J. A. (2012): Arqueología del campesinado medieval: la aldea de Zaballa. Bilbao, Universidad del País Vasco.

Quirós, J. A. (2015): Informe 2015 del proyecto arqueológico de Torrentejo, Labastida. Bibat, Museo de Arqueología, Registro General de Entrada 19 de 04/01/2016.

Quirós, J. A. (2018): Arqueología de una comunidad campesina medieval: Zornoztegi (Álava). Bilbao, Universidad del País Vasco, en prensa.

Quirós, J. A. y Santos, I. (2015): "Founding and Owning Churches in Early Medieval Álava (North Spain): The Creation, Transmission, and Monumentalization of Memory", en Sánchez-Pardo, J. C. y Shapland, M., Churches and Social Power in Early Medieval Europe. Integrating Archaeological and Historical Approaches: 35-68. Turnhout, Brepols.

Reynolds, A. y Quirós, J. A. (2010): Memoria final del proyecto arqueológico de Aistra (Zalduondo, Álava). Bibat, Museo de Arqueología, Registro General de Entrada 995 de 28/12/2010. 
Ripoll, G. y Velázquez, I. (1999): “Origen y desarrollo de las parrochiae en la Hispania de la Antigüedad Tardía", en P. Pergola (ed.), Alle origini della parrocchia rurale (IV-VIII sec). Atti della giornata temática dei Seminari di Archeologia Cristiana: 101165. Roma (1998), Città del Vaticano, Pontificio Istituto di Archeologia Cristiana.

Rodríguez y Rodríguez de Lama, I. (1989): Colección diplomática medieval de La Rioja. Tomo IV: documentos del siglo XIII. Logroño, Instituto de Estudios Riojanos.

Rodríguez y Rodríguez de Lama, I. (1992): Colección diplomática medieval de La Rioja. Tomo II. Documentos (923-1168), $2^{\mathrm{a}}$ edición revisada y aumentada. Logroño, Instituto de Estudios Riojanos.

Ruiz de la Peña, J. I. (1993): "Parroquias, concejos parroquiales y solidaridades vecinales en la Asturias medieval". Asturiensia Medievalia 7: 105-122.

Ruiz de la Peña, J. I. (2008): "La parroquia, célula de encuadramiento de la sociedad rural asturiana", en J. Á. Sesma y Laliena, C. (eds.), La pervivencia del concepto. Nuevas reflexiones sobre la ordenación social del espacio en la Edad Media: 197-217. Zaragoza, Gobierno de Aragón.

Sánchez Zufiaurre, L. (2007): Técnicas constructivas medievales. Nuevos documentos arqueológicos para el estudio de la Alta Edad Media en Álava. Bilbao, Gobierno Vasco.

To Figueras, Ll. (1991): "El marc de les comunitats pageses: villa i parròquia en les diòcesis de Girona $\mathrm{i}$ Elna (final del segle IX - principi del'XI)", en Catalunya i França meridional a l'entorn de l'any mil. Actes del Col·loqui Internacional Hug Capet: 212239. Barcelona (1987), Barcelona, Generalitat de Catalunya.

Utrero, M. A. (2006): Iglesias tardoantiguas y altomedievales en la Península Ibérica. Analisis arqueológico y sistemas de abovedamiento. Anejos del Archivo Español de Arqueología XL. Madrid, Consejo Superior de Investigaciones Científicas.

Villaginés, J. (1988): “El Fenomen parroquial en la societat del Vallès Oriental a l'alta Edat Mitjana (ss. XI i XII)". Acta historica et archaeologica mediaevalia IX: 125-142.

Wood, S. (2006): The Proprietary Church in the Medieval West. Oxford, Oxford University Press.

Zadora-Rio, E. (2008): "Conclusion generale", en Zadora-Rio, E. (ed.), Des paroisses de Touraine aux communes d'Indre-et-Loire. La formation des territoires. 34e supplément à la Revue Archéologique du Centre de la France. Paris, RACF. 